\title{
Triple-component Mixed Neuroendocrine-Nonneuroendcocrine Neoplasm of the duodenum: A rare case report
}

\author{
Souhir Khemiri ${ }^{1}$, Sonda Masmoudi ${ }^{1}$, Asma Yaich ${ }^{2}$, Ons Boudawara ${ }^{1}$, Samir Aloulou ${ }^{3}$, and \\ afef khanfir ${ }^{4}$ \\ ${ }^{1}$ Habib Bourguiba Hospital \\ ${ }^{2}$ hopital regional gabes \\ ${ }^{3}$ hopital regional gabes tunisia \\ ${ }^{4}$ University of Sfax Faculty of Medecine of Sfax
}

September 25, 2021

\begin{abstract}
Mixed neuroendocrine-non-neuroendocrine neoplasms (MiNEN) are an heterogeneous subgroup of rare neoplasms. Triple componed MiNEN associating neuroendocrine tumor, adenocarcinoma and squamous cell carcinoma are rarely described in the literature. Here we present the unique case of a 56-year-old women with neuroendocrine tumor, adenocarcinoma and squamous cell carcinoma of the duodenum
\end{abstract}

Triple-component Mixed Neuroendocrine-Nonneuroendcocrine Neoplasm of the duodenum: A rare case report

Corresponding author : Souhir Khemiri, Medical oncology department, CHU habib Bourguiba Sfax, Tunisia, e-mail :souhirmed@gmail.com

Authors :

1. Souhir Khemiri, Medical oncology department, CHU habib Bourguiba Sfax

2. Sonda Masmoudi, Medical oncology department, CHU habib Bourguiba Sfax

3. Asma Yaich, Medical oncology department, CHU Gabes, Gabes

4. Ons Boudawara, Anatomopathology department, CHU Habib Bourguiba, sfax

5. Samir aloulou, Medical oncology department, CHU Gabes, Gabes

6. Afef Khanfir, Medical oncology department, CHU habib Bourguiba Sfax

Key clinical message :

A special attention to histologic characteristics and immunocytochemistry of digestive tumors may arise the number of cases diagnosed with MiNEN to improve its treatment and allow making clear recommandations.

\section{Introduction}

Neuroendocrine neoplasms form an heterogeneous group of neoplasms that represent $1 \%$ of all digestive malignancies [1]. Mixed neuroendocrine-non-neuroendocrine neoplasms (MiNEN), are defined by the combinition of at least two morphologically different neoplastic components, including a neuroendocrine component usually poorly differentiated neuroendocrine carcinoma [2-6]. The non-endocrine component is mostly adenocarcinoma. Squamous cell carcinoma is rarely associated [7]. Evidence from the literature on MiNENs is almost derived from case reports and small retrospective series. Due to the rarity of this diagnosis and 
the limited quality of published data, the epidemiology, prognosis, and best therapeutic management of patients with MiNEN remains not well defined. They are usually highly aggressive with poor prognosis and survival close to those of pure neuroendocrine carcinomas [6]. For these reasons, MiNENs with neuroendocrine carcinoma are usually treated similarly to their pure neuroendocine part [8]. Alternatively, when the non-endocrine component is the preponderant and/or most aggressive histology, some clinicians choose to manage these tumors as the non-neuroendocrine tumors from the same site of origin [6]. Both practices are based on principles of histological analogy, but are not supported by evidence from prospective randomised trials. In this paper, we present a rare case of duodenal MiNEN with triple component neuroendocrine hepatic metastases and a brief review of the literature.

\section{Case description}

A 56-year-old woman was admitted to the hospital on September 2018 complaining of asthenia, abdominal pain, jaundice, and billinuria. The lab results revealed increased levels of liver function test. Abdominal echography showed dilatation of intra and extra hepatic bile ducts and of pancreatic duct without evident obstacle. Bili-MRI and Abdominal CT showed similar results. Upper gastrointestinal endoscopy showed a tumor sized $3 \mathrm{~cm}$ in the second part of duodenum with swollen papilla wich was biopsied. Pathological findings of the endoscopic biopsy of the tumor showed well differentiated high grade (Grade3) neuroendocrine tumor. It was not associated with carcinoid syndrome. Chest, abdomen and pelvic CT scan concluded at localised disease. Pancreaticoduodenectomy was performed. The histological examination showed that the tumor comprised three components that are intimately intermingled but all three phenotypes are well recognisable as three distinct histological tumours : well-differentiated grade three neuroendocrine tumor (40\%), intestinal adenocarcinoma (30\%) and keratinising squamous cell carcinoma (30\%). Immunohistochemically, the tumor stained positive for chromogranin, synaptophysin, keratin and CD56. The ki67 of the neuroendocrine component was of $80 \%$ (figure1).

Two locoregional lymph nodes were involved. The surgical margins of the specimen were tumor-free. The tumor was classified as pT3 pN1 M0. She underwent an adjuvant chemotherapy based on 5-Fluorouracil and oxaliplatin (Folfox protocol). After 8 cycles of chemotherapy (4 months of treatment), an enlargement of left supraclavicular lymph node was notedin physical examination. CT confirmed the disease progression with involvement of supraclavicular and mediastinal lymph nodes and lung. A biopsy of supraclavicular lymph node was performed. The histological examination showed that adenocarcinoma was the only component of the metastases. A second line chemotherapy with Folfiri protocol were administrated. CT performed after 6 cycles showed a a radiological progression of both lymph nodes and pulmonary involvement. We decide to A third line chemotherapy with gemcitabine and cisplatin was administrated. The patient consulted after the third cycle of this regimen with weakness of the left upper limb. MRI of the brain and spine showed frontal brain and vertebral metastases with dorsal spinal cord compression. So, she was offered palliative radiation, then a fourth line chemotherapy with capecitabine was initiated. After 4 cycles of chemotherapy, she didn't show evidence of any response and progressive deteriorating of general condition was installed. She died 18 months postoperatively.

\section{Discussion}

The first description of a gastrointestinal neoplasm with a neuroendocrine and a non-neuroendocrine components was published by Cordier in 1924 [9]. Since then, a significant number of cases have been reported in the literature, and the recognition of MiNENs has been increasing in pathology practice. For these reasons, digestive MiNENs are better characterized than those arising in other sites.

The term mixed adenoneuroendocrine carcinoma (MANEC) was initially proposed in the 2010 WHO classification 8to define this category of mixed neoplasm [10]. In fact, this term does not convey the heterogeneity of digestive mixed neoplasms and has created some misunderstanding among both pathologists and clinicians as it seems to imply that all the MANECs are composed of adenocarcinoma and neuroendocrine carcinoma. Although the association of adenocarcinoma and neuroendocrine carcinoma is the most frequent, the spectrum of mixed neoplasms, other combinations between neuroendocrine neoplasms (neuroendorine tumor or 
carcinoma) and other epithelial tumors from the same site of origin have been described. Then, the term MANEC does not adequately represent this heterogeneity. In 2017, the WHO renamed MANECs as MiNENs where the $30 \%$ threshold for each component was maintained [11].

However, identification of the neuroendocrine component in tubular adenocarcinomas is not easily performed because the neuroendocrine cells are not always immunoreactive for specific markers, with the reported rate of positivity being 60\%-70\% for chromogranin, $75 \%-90 \%$ for synaptophysin, and 50\% for CD56[12-14]. In our case, the tumor stained positive for chromogranin, synaptophysin, keratin and CD56 and the ki67 of the neuroendocrine component was of $80 \%$.

The origin of MiNEN remains uncertain. There are two main theories regarding the origin of these neoplasms [15-17]. The first theory suggested that the neuroendocrine and non neuroendocrine components originate independly from two different cell lines. Based on the second hypothesis, the two different derive from a common pluripotent stem cell progenitor, which acquires biphenotypicdifferentiation during carcinogenesis which is affected by hormones, the local microenvironment and an instable genome during the process of tumor occurrence and development, eventually leading to a two-way or multidirectional differentiation. We can postulate that our duodenal MiNEN, composed of three histologically distinct tumours but intimately mixed together, is most likely derived from a common pluripotent stem cell. A very few cases of MiNENs with triple components have been previously described in the literature mostly gastric tumors [18-25]. To our knowledge, this is the first case of triple component MiNEN described in the duodenum. It is also known that a neoplasm's surrounding area is altered, influencing cancer growth and contributing to epithelial instability (26-28) . Therefore, it is plausible that a pool of initiated cells in an area may be stimulated by an altered microenvironment, ultimately resulting in a second neoplasm that can grow until it collides with the first tumor. Although knowing which component appeared first in this case is impossible, it is probable that the first neoplasm contributed to the rise and growth of the second.

As these neoplasms are almost exclusively described on case reports and small retrospective studies, the natural history of the duodenal MiNENs is also still unclear as much as histogenesis. Vanoli A.et al [29], showed on a review about duodenal neuroendocrine neoplasms that MiNENs of the ampullary region are aggressive neoplasms. They are generally presenting at advanced stage and displaying a reserved prognosis, with a median survival of only 10-15 months [30-32] In our case, the clinical behaviour seemed to depend on the adenocarcinoma component. The fine needle aspiration of one of the lymph node had demonstrated the nature of the metastases. The survival was of 18 months postoperatively. Kim and Chae [33] have recently published similar findings: the NEC component of their gastric MANEC had shown more aggressive features, invading into the serosa and the lymphatic glands, whereas the glandular carcinoma was confined to the mucosa and submucosa. Volante et al. [3] reported that the clinical behaviour of mixed neoplasms depends on the non neuroendocrine component if the associated endocrine component is well differentiated and upon the neuroendocrine component if it is poorly differentiated.

The optimal management strategy for patients with a MiNEM remains unknown [7]. Lee and al [34] have suggested that treatment should focus on the more aggressive cells of the tumor since the clinical behavior of this mixed tumor follows that of the more aggressive component. The present patient underwent pancreaticoduodenctomy with no surgical complications and received adjuvant chemotherapy after surgery, but the deasese was progressed and the patient died of tumor progression within 2 years.

\section{Conclusion}

In summary, we reported an extremely rare case of triple component MiNEN of duodenum wich showed an agressive behavior. The standardization of treatment of such tumors is required and needs further investigations to improve their prognosis.

- data availability statement : yes

- No funding statement

- No conflict of interest disclosure

- No ethics approval statement 
- No patient consent statement

- Author contribution : all the authors have contributed to this work

\section{References :}

1. Lepage C, Bouvier AM, Faivre J: Endocrine tumours: epidemiology of malignant digestive neuroendocrine tumours. Eur J Endocrinol 2013;168:R77-R83.

2. Klöppel G, Couvelard A, Hruban RH, Klimstra DS, Komminoth P, Osamura RY, et al: Neoplasms of the neuroendocrine pancreas; in WHO Classification of Tumours of the Endocrine Organs, ed 4. Lyon, IARC Press, 2017, pp 210-239.

3. Volante M, Rindi G, Papotti M: The grey zone between pure (neuro)endocrine and non- (neuro)endocrine tumours: a comment on concepts and classification of mixed exocrine-endocrine neoplasms. Virchows Arch 2006;449:499-506.

4. Volante M, Righi L, Asioli S, Bussolati G, Papotti M: Goblet cell carcinoids and other mixed neuroendocrine/nonneuroendocrine neoplasms. Virchows Arch 2007;451:61-69.

5. Lewin K: Carcinoid tumors and the mixed (composite) glandular-endocrine cell carcinomas. Am J Surg Pathol 1987; 11(suppl 1):71-86.

6. La Rosa S, Marando A, Sessa F, Capella C: Mixed adenoneuroendocrine carcinomas (MANECs) of the gastrointestinal tract: an update. Cancers 2012;4:11-30

7. Frizziero M, Chakrabarty B, Nagy B, et al. Mixed Neuroendocrine Non-Neuroendocrine Neoplasms: A Systematic Review of a Controversial and Underestimated Diagnosis. JCM. 2020;9(1):273.

8. Garcia-Carbonero, R.; Sorbye, H.; Baudin, E.; Raymond, E.;Wiedenmann, B.; Niederle, B.; Sedlackova, E.; Toumpanakis, C.; Anlauf, M.; Cwikla, J.B.; et al. ENETS Consensus Guidelines for High-Grade Gastroenteropancreatic Neuroendocrine Tumors and Neuroendocrine Carcinomas. Neuroendocrinology 2016, 103, 186-194.

9. Cordier R : Les cellules argentaffines dans les tumeurs intestinales. Arch Int Med Exp 1924 1:5.

10. Rindi G, Arnold R, Bosman FT, Capella C, Klimstra DS, Klöppel G, Komminoth P, Solcia E (2010) Nomenclature and classification of neuroendocrine neoplasms of the digestive system. In Bosman FT, Carneiro F, Hruban RH, Theise ND (eds) WHO classification of tumours of the digestive system, 4th edn. IARC Press, Lyon, pp 13-14

11. Lloyd, R.V.; Osamura, R.Y.; Klöppel, G.; Rosai, J. Who Classification of Tumours of Endocrine Organs, 4th ed.; International Agency for Research on Cancer (IARC): Lyon, France, 2017.

12. Kitajima T, Kaida S, Lee S, Haruta S, Shinohara H, Ueno M, Suyama K, Oota Y, Fujii T, Udagawa H. Mixed adeno(neuro)endocrine carcinoma arising from the ectopic gastric mucosa of the upper thoracic esophagus. World J Surg Oncol. 2013;11:218.

13. Wang YH, Lin Y, Xue L, Wang JH, Chen MH, Chen J. Relationship between clinical characteristics and survival of gastroenteropancreatic neuroendocrine neoplasms: A single-institution analysis (1995-2012) in South China. BMC Endocr Disord. 2012;12:30.

14. Kim JJ, Kim JY, Hur H, Cho YK, Han SU. Clinicopathologic significance of gastric adenocarcinoma with neuroendocrine features. J Gastric Cancer. 2011;11:195-199.

15. Furlan D, Cerutti R, Genasetti A, Pelosi G, Uccella S, La Rosa S and Capella C: Microallelotyping defines the monoclonal or the polyclonal origin of mixed and collision endocrine-exocrine tumors of the gut. Lab Invest. 83:963-971. 2003.

16. Paniz Mondolfi AE, Slova D, Fan W, Attiyeh FF, Afthinos J, Reidy J, Pang Y and Theise ND: Mixed adenoneuroendocrine carcinoma (MANEC) of the gallbladder: A possible stem cell tumor? Pathol Int. 61:608-614. 2011.

17. Vanacker L, Smeets D, Hoorens A, Teugels E, Algaba R, Dehou MF, De Becker A, Lambrechts D and De Greve J: Mixed adenoneuroendocrine carcinoma of the colon: Molecular pathogenesis and treatment. Anticancer Res. 34:5517-5521. 2014.

18. Haratake J, Horie A, Inoshita S: Gastric small cell carcinoma with squamous and neuroendocrine differentiation. Pathology 1992;24:116-120.

19. Shibuya H, Azumi N, Abe F: Gastric small-cell undifferentiated carcinoma with adeno and squamous 
cell carcinoma components. Acta Pathol Jpn 1985;35:473-480

20. Farooq, F.; Zarrabi, K.; Sweeney, K.; Kim, J.; Bandovic, J.; Patel, C.; Choi, M. Multiregion Comprehensive Genomic Profiling of a Gastric Mixed Neuroendocrine-Nonneuroendocrine Neoplasm with Trilineage Differentiation. J. Gastric Cancer 2018, 18, 200-207

21. Zhang,W.; Xiao,W.; Ma, H.; Sun, M.; Chen, H.; Zheng, S. Neuroendocrine liver metastasis in gastric mixed adenoneuroendocrine carcinoma with trilineage cell di_erentiation: A case report. Int. J. Clin. Exp. Pathol. 2014, 7, 6333-6338.

22. Pericleous M, Toumpanakis C, Lumgair H, et al. Gastric Mixed Adenoneuroendocrine Carcinoma with a Trilineage Cell Differentiation: Case Report and Review of the Literature. Case Rep Oncol. 2012;5(2):313-319.

23. Bae HI, Lee C, Jo YM, Kwon O, Yu W, Kim MS, et al. Gastric mixed adenoneuroendocrine carcinoma with squamous differentiation: a case report. J Pathol Transl Med 2016;50:318-321.

24. Shintaku M, Kataoka K, Kawabata K. Mixed adenoneuroendocrine carcinoma of the gallbladder with squamous cell carcinomatous and osteosarcomatous differentiation: Report of a case: MANEC of the gallbladder. Pathol Int. 2013;63(2):113-119.

25. Mouyed Alawad, MD, Scott Schoninger, Raavi Gupta, MD, Mixed Neuroendocrine-Nonneuroendocrine Carcinoma Arising in the Gallbladder: A Rare Case of a Three-Component Composite Neoplasm, American Journal of Clinical Pathology, Volume 152, Issue Supplement_1, October 2019, Page S121.

26. Hassan MM, Phan A, Li D, Dagohoy CG, Leary C, Yao JC. Risk factors associated with neuroendocrine tumors: A U.S.-based case-control study. Int J Cancer. 2008. 15;123:867-73.

27. Naritaka Y, Ogawa K, Shimakawa T, Wagatsuma Y, Isohata N, Asaka S, et al. Collision carcinoma of the residual cervical esophagus 27 years after esophageal cancer surgery. Anticancer Res. 2007;27:50511.

28. González LM, Sanz-Esponera J, Saez C, Alvarez T, Sierra E, Sanz-Ortega J. Case report: esophageal collision tumor (oat cell carcinoma and adenocarcinoma) in Barrett's esophagus: immunohistochemical, electron microscopy and LOH analysis.Histol Histopathol. 2003;18:1-5.

29. Vanoli A. Duodenal Neuroendocrine Neoplasm. In: van Krieken JHJM, ed.Encyclopedia of Pathology . Springer International Publishing; 2020:1-8.

30. Nassar, H., Albores-Saavedra, J., \& Klimstra, D. S. (2005). High-grade neuroendocrine carcinoma of the ampulla of vater: A clinicopathologic and immunohistochemical analysis of 14 cases. The American Journal of Surgical Pathology, 29, 588-594.

31. Vanoli, A., La Rosa, S., Klersy, C., Grillo, F., Albarello, L., Inzani, F., Maragliano, R., Manca, R., Luinetti, O., Milione, M., Doglioni, C., Rindi, G., Capella, C., \& Solcia, E. (2017). Four neuroendocrine tumor types and neuroendocrine carcinoma of the duodenum: Analysis of 203 cases. Neuroendocrinology, 104, 112-125.

32. Mahansaria, S. S., Agrawal, N., Arora, A., Bihari, C., Appukuttan, M., \& Chattopadhyay, T. K. (2017). Ampullary mixed adenoneuroendocrine carcinoma: Surprise histology, familiar management. International Journal of Surgical Pathology, 25, 585-591

33. Kim TY, Chae HD: Composite neuroendocrine carcinoma with adenocarcinoma of the stomach misdiagnosed as a giant submucosal tumor. J Gastric Cancer 2011;11:126-130.

34. Lee HH, Jung CK, Jung ES, Song KY, Jeon HM, Park CH. Mixed exocrine and endocrine carcinoma in the stomach: a case report. J Gastric Cancer. 2011;11:122-125

\section{Hosted file}

Figure1. docx available at https: //authorea.com/users/437612/articles/539124-triple-componentmixed-neuroendocrine-nonneuroendcocrine-neoplasm-of-the-duodenum-a-rare-case-report 